\title{
Effect of Graphene Oxide Thin Film on Growth and Electrochemical Performance of Hierarchical Zinc Sulfide Nanoweb for Supercapacitor Applications
}

Iqbal, Muhammad F.; Mahmood-Ul-Hassan; Razaq, Aamir; Ashiq, Muhammad N.; Kaneti, Yusuf; Azhar, Azhar A.; Yasmeen, Farhat; Joya, Khurrum Saleem; Abbass, Shafqat

Published in:

ChemElectroChem

Link to article, DOI:

10.1002/celc.201800633

Publication date:

2018

Document Version

Peer reviewed version

Link back to DTU Orbit

Citation (APA):

Iqbal, M. F., Mahmood-Ul-Hassan, Razaq, A., Ashiq, M. N., Kaneti, Y., Azhar, A. A., Yasmeen, F., Joya, K. S., \& Abbass, S. (2018). Effect of Graphene Oxide Thin Film on Growth and Electrochemical Performance of Hierarchical Zinc Sulfide Nanoweb for Supercapacitor Applications. ChemElectroChem, 5(18), 2636-2644. https://doi.org/10.1002/celc.201800633

\section{General rights}

Copyright and moral rights for the publications made accessible in the public portal are retained by the authors and/or other copyright owners and it is a condition of accessing publications that users recognise and abide by the legal requirements associated with these rights.

- Users may download and print one copy of any publication from the public portal for the purpose of private study or research.

- You may not further distribute the material or use it for any profit-making activity or commercial gain

- You may freely distribute the URL identifying the publication in the public portal 


\section{FUNDAMENTALS \& APPLICATIONS \\ CHEMELECTROCHEM}

ANALYSIS \& CATALYSIS, BIO \& NANO, ENERGY \& MORE

\section{Accepted Article}

Title: Excellent Effect of Graphene Oxide Thin Film on Growth and Electrochemical Performance of Hierarchical Zinc Sulfide Nanoweb for Supercapacitor Applications

Authors: Muhammad Faisal lqbal, mahmood ul Hassan, Aamir Razaq, Muhammad Naeem Ashiq, Farhat Yasmeen, Khurrum

Saleem Joya, Shafqat Abbass, Yusuf Valentino Kaneti, and Azhar Alowasheeir Azhar

This manuscript has been accepted after peer review and appears as an Accepted Article online prior to editing, proofing, and formal publication of the final Version of Record (VoR). This work is currently citable by using the Digital Object Identifier (DOI) given below. The VoR will be published online in Early View as soon as possible and may be different to this Accepted Article as a result of editing. Readers should obtain the VoR from the journal website shown below when it is published to ensure accuracy of information. The authors are responsible for the content of this Accepted Article.

To be cited as: ChemElectroChem 10.1002/celc.201800633

Link to VoR: http://dx.doi.org/10.1002/celc.201800633 


\section{Excellent Effect of Graphene Oxide Thin Film on Growth and Electrochemical Performance of Hierarchical Zinc Sulfide Nanoweb for Supercapacitor Applications}

Muhammad Faisal Iqbal*abc, Dr. Mahmood-Ul-Hassan ${ }^{\text {a }}$, Dr. Aamir Razaq ${ }^{\text {d }}$, Dr. Muhammad Naeem Ashiq*e, Dr. Yusuf Valentino Kaneti ${ }^{\mathrm{b}}$, Azhar Alowasheeir Azhar ${ }^{\mathrm{b}}$, Dr. Farhat Yasmeen $^{\mathrm{f}}$, Dr. Khurrum Saleem Joya ${ }^{\mathrm{f}, \mathrm{g}, \mathrm{h}}$, Shafqat Abbass ${ }^{\mathrm{e}}$

a Materials Growth and Simulation Laboratory, Department of Physics, University of The Punjab, Lahore 54590, Pakistan

${ }^{\mathrm{b}}$ International Center for Materials Nanoarchitectonics (MANA), National Institute for Materials Science (NIMS), 1-1 Namiki, Tsukuba, Ibaraki 305-0044, Japan

${ }^{c}$ Department of Physics, Lahore Garrison University, Sector C, DHA Phase-VI Lahore, Pakistan

${ }^{\mathrm{d}}$ Department of Physics, COMSATS Institute of Information Technology, Lahore 54000, Pakistan

e Institute of Chemical Sciences, Bahauddin Zakariya University, Multan 60800, Pakistan

${ }^{\mathrm{f}}$ University of Engineering and Technology, Institute of Environmental Engineering and Research, GT Road, 54890 Lahore, Punjab, Pakistan

g Department of Energy Conversion and Storage, Denmark Technical University (DTU), Roskilde, Denmark

${ }^{\mathrm{h}}$ Department of Chemistry, King Fahad University of Petroleum and Minerals (KFUPM), Dhahran, Saudi Arabia

$*=$ Corresponding Author

E-mail: faisal.phd.physics@pu.edu.pk (Muhammad Faisal Iqbal), naeembzu@bzu.edu.pk, (Muhammad Naeem Ashiq), khurramdtu@gmail.com (Khurram S Joya)

Phone \#: +92-300-9879344

Fax \#: +92-61-9210068 


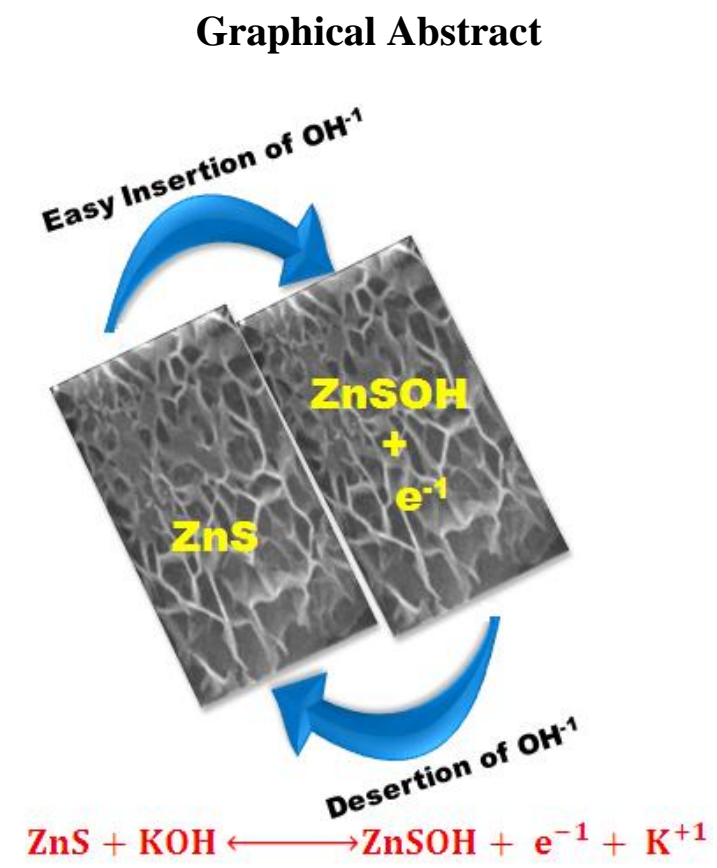

\section{Abstract}

Surface morphological induced electrical conductivity and specific surface area of a material play a significant role to facilitate electrochemical behavior for supercapacitors applications. Therefore, the synthesis step for controlling such parameters becomes very imperative and challenging. Herein, $\mathrm{ZnS}$ nanoweb is deposited directly on $\mathrm{Ni}$ foam having pre-deposited graphene oxide thin layer developed via hydrothermal method. The structure and surface morphology of modified $\mathrm{ZnS}$ is observed using, respectively, XRD and SEM. The electrical conductivity determined for graphene oxide supported $\mathrm{ZnS}$ nanoweb, using four probes method, is $100.15 \mathrm{Scm}^{-1}$, while the specific surface area is $104.42 \mathrm{~m}^{2} \mathrm{~g}^{-1}$ by BET measurements. Pseudocapacitive behavior is monitored by cyclic voltammetry, and the excellent specific capacity of $3052 \mathrm{Fg}^{-1}$ has been found at the scan rate $2 \mathrm{mVs}^{-1}$, while it is $2400.30 \mathrm{Fg}^{-1}$ according the galvanostatic charge-discharge profile at (current density) 3 $\mathrm{mAcm}^{-2}$, which significantly higher than those measured for bare GO or $\mathrm{ZnS}$ layers. The energy and power densities of GO supported $\mathrm{ZnS}$ nanoweb, determined using three electrode systems, are $120 \mathrm{WhKg}^{-1}$ at $3 \mathrm{mAcm}^{-2}$ and $4407.73 \mathrm{Wkg}^{-1}$, respectively. The symmetric 
behavior using two electrode systems show an energy density $20.29 \mathrm{WhKg}^{-1}$ at $2 \mathrm{mAcm}^{-2}$. Hence, both symmetric and asymmetric measurements suggest that GO supported $\mathrm{ZnS}$ nanoweb can be applied as the suitable electrode for supercapacitors.

Keywords: Energy Density; Graphene oxide; Specific Capacitance; Supercapacitor; Zinc Sulfide

\section{Introduction}

Energy storage devices have been proven backbone for addressing the existing energy crises and for supplying energy during shutdown of the traditional electricity. Energy storage devices are most suited to supply energy to various electronic devices, electrical vehicles and heavy industries.1-4 Among the various existing devices involving various energy storing mechanisms e.g., batteries, traditional capacitors, supercapacitors and the fuel cell etc., the supercapacitors are considered most attractive due to their light weight, low price and high capacitance, capability for simultaneously maintaining the both energy and power density and significantly large life cycles. 2, 5-7 The main categories of supercapacitors, which is dependent upon the existing energy storage phenomena, are electric double layer supercapacitors (EDLCs) and pseudocapacitors. In the first category, an electrochemical double layer formed by electrolyte ions appears at the electrode surface instead of the electronic flow between the electrolyte and electrode surface. In contrast, this second category involves faradaic reaction at the electrode surface. 8-10

The electrochemical nature of the investigated electrode is fundamental because it decides the efficiency of a supercapacitor. Different materials including carbonaceous, polymers, metal oxides, metal organic framework (MOFs), metal sulfides and different composites, have been investigated to expose the potential electrode applications in supercapacitors. 11-15 However, due to various limitations in the materials, practical 
applications are restricted. For example, carbonaceous electrodes are suited only for EDLCs with low specific capacitance, oxides and MOFs (expensive and difficult fabrication) exhibit poor electrical conductivity. 8, 16-20 Although metal sulfides show fairly well electrical conductivity but the electrochemical performance can be further enhanced by realizing higher electrical conductivity and specific surface area values. Carbonaceous materials (e.g., graphene oxide (GO)), exhibit a variety of potential applications, e.g., photoelectrocatalytic activity and vivo-bio imaging, which are due to the large specific surface area and high electrical conductivity. 21-24 Hence, with the use of GO, the improved electrochemical nature of the electrodes in supercapacitors could be anticipated. 2, 3, 25, 26 Furthermore, the extensive literature survey shows scarcity of the reports on metallic sulfides for electrochemical applications but they faced problems with electrode stability which can be improved by transition metal sulfides. 27,28

Herein, GO thin layer was initially prepared on a flexible nickel foam (NF), and then ZnS nanoweb were deposited on it using hydrothermal route. The structure and surface characteristics were explored using X-ray diffraction (XRD) and scanning electron microscopy (SEM), respectively. Elemental atomic ratio was observed by energy dispersive X-ray technique (EDX). Moreover, the electrical conductivity exhibited, the stabilized specific surface area and the measured electrochemical natures of individual $\mathrm{ZnS}$ on NF have been contrasted with those for GO supported $\mathrm{ZnS}$ nanoweb on NF substrate to elucidate the practical significance of the designed system.

\section{Results and Discussion}

The XRD pattern of GO supported ZnS synthesized on NF substrate measured using X-ray diffractometer (Rigaku Smart lab) is depicted in Fig. 1. The diffraction peaks appeared at $10.40^{\circ}, 28.90^{\circ}, 44.41^{\circ}, 51.93^{\circ}$ and $76.38^{\circ}$. The diffraction peak at $10.40^{\circ}$ are indicative of $\mathrm{GO}$, while $2 \theta$ values at $28.90^{\circ}, 51.93^{\circ}$ and $76.38^{\circ}$ were assigned to the hexagonal $\mathrm{ZnS}$ 
crystallographic planes (lll $\left.\begin{array}{lll}0 & 2\end{array}\right),\left(\begin{array}{lll}1 & 0 & 3\end{array}\right)$ and $\left(\begin{array}{lll}2 & 1 & 0\end{array}\right)$, respectively, which was decided due to consistency with JCPDS card no. 00-001-0677. Moreover, the diffraction peaks appearing at $44.41^{\circ}$ and the shoulder of the diffraction peak at $76.38^{\circ}$ are originating from NF substrate. Similarly, individual ZnS fabricated on NF substrate exhibited a similar XRD pattern (see Fig. S1 in the supporting file), however the GO peak was absent expectedly, confirming the accuracy of the XRD pattern (Fig. 1).

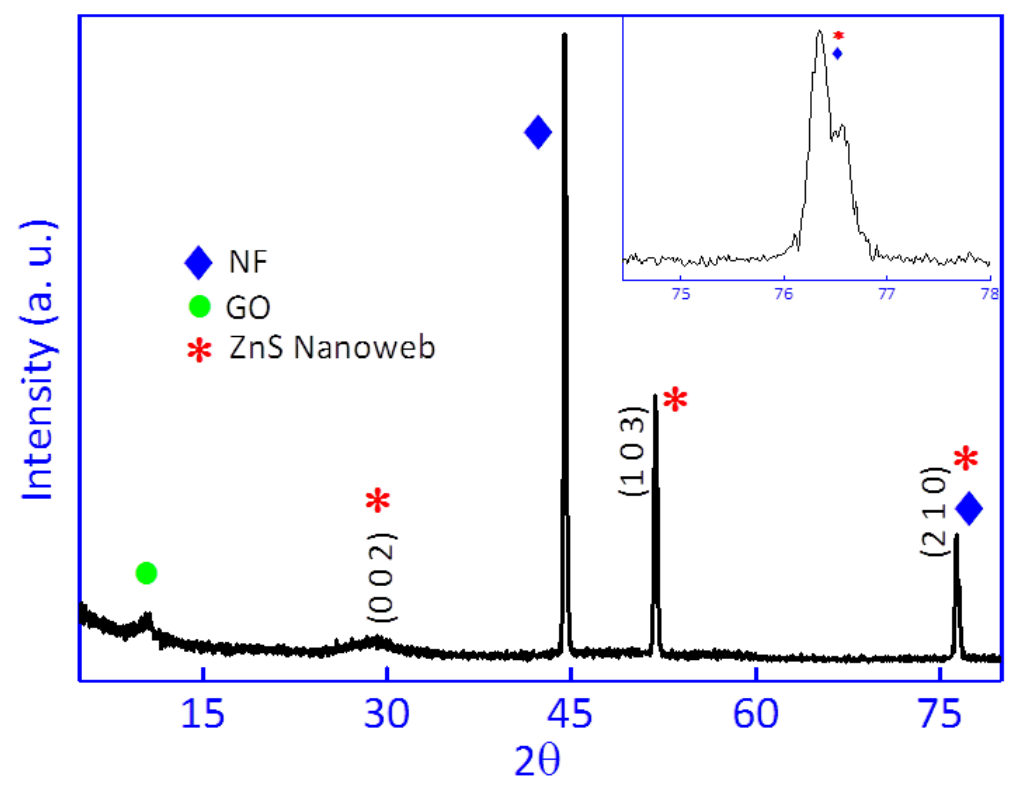

Figure 1: XRD pattern of GO supported ZnS nanoweb prepared on a NF substrate.

Surface morphology is a significant feature because it critically affects the specific properties of material for certain applications. The surface morphological study of GO supported $\mathrm{ZnS}$ nanoweb and individual $\mathrm{ZnS}$ fabricated on nickel foam (NF) substrate was conducted using scanning electron microscopy (SEM) and the measured images are shown in Fig. 2. The surface morphology of NF and GO thin observed by using SEM has been given in Fig. S2. GO thin film showed some cracks arising due to the porous nature of NF. The measured SEM images, shown in Fig. 2 (a \& b) with two different magnifications, illustrated nanoweb like surface morphology of the GO supported ZnS fabricated on NF substrate. On the other hand, surface morphology of the ZnS directly fabricated on bare NF, as shown in Fig. 2 (c \&d) 
exhibited nano granular structure having broad variations in the size and shape. Hence, it was evident that GO thin film adsorbed on to the NF substrate created large active sites for the good adhesion of $\mathrm{ZnS}$ and resulting in the nanoweb like surface structure. 29

Elemental mapping of $\mathrm{GO}$ supported $\mathrm{ZnS}$ and individual $\mathrm{ZnS}$ has been carried out by $\mathrm{Fe}$ SEM with EDX (SU8000). EDX elemental mapping correspond that atomic ratio of $\mathrm{Ni}, \mathrm{C}$, $\mathrm{Zn}$ and $\mathrm{S}$ in GO supported $\mathrm{ZnS}$ nanoweb electrode was 47.39, 43.17, 6.41 and 3.03 \% (Fig. 2 (e)). While in case of individual $\mathrm{ZnS}$, atomic ratio of $\mathrm{Ni}, \mathrm{Zn}$ and $\mathrm{S}$ was $76.91,14.10$ and 9.00 $\%$ (Fig. 2 (f)). As atomic ratio of $\mathrm{Zn}$ and $\mathrm{S}$ was higher in individual $\mathrm{ZnS}$, which may be due to porous type nature of nickel foam substrate but it was covered by GO in composite form as GO supported ZnS nanoweb. 

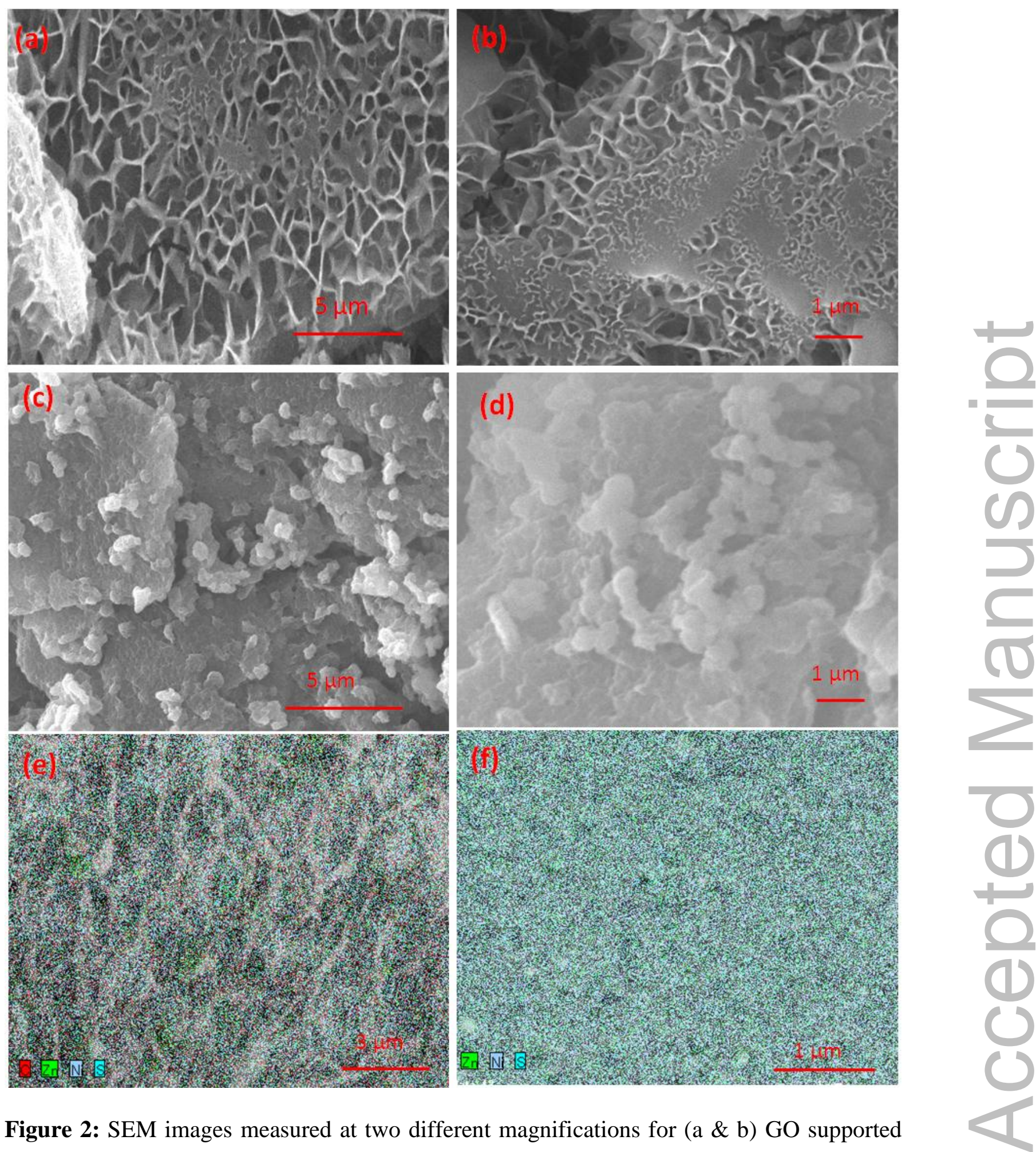

Figure 2: SEM images measured at two different magnifications for (a \& b) GO supported ZnS nanoweb on NF substrate and (c \& d) individual ZnS grains. EDX mapping for (e) GO supported $\mathrm{ZnS}$ nanoweb and (f) individual $\mathrm{ZnS}$ on NF substrate. 
The electrical conductivity of individual $\mathrm{ZnS}$ and GO supported $\mathrm{ZnS}$ nanoweb is measured using four-probe technique to know the electrochemical nature of the electrodes for supercapacitors application. The electrical conductivity measured for individual $\mathrm{ZnS}$ and GO supported $\mathrm{ZnS}$ nanoweb on NF was 43.46 and $100.15 \mathrm{Scm}^{-1}$, respectively. As apparent from the measured conductivity values, the GO being a good conducting material enhances the conductivity of $\mathrm{ZnS}$ nanoweb developed on it, relative to $\mathrm{ZnS}$, which showed less electrical conductivity while being a semiconductor. 30 It is assumed that the presence of GO under layer resulted an easy charge carrier flow through the $\mathrm{ZnS}$ nanoweb structure that enhanced the electrical conductivity. As GO is characterized as having p-type nature, while $\mathrm{ZnS}$ exhibits n-type semiconducting character, therefore, at their interface Fermi level needs shifting causing carrier flow, owing to which the electrical conductivity of $\mathrm{ZnS}$ nanoweb is enhanced. 27

The specific surface area of GO supported $\mathrm{ZnS}$ nanoweb and simple $\mathrm{ZnS}$ prepared on NF substrate has been determined by $\mathrm{N}_{2}$ absorption/desorption isotherms curves (See Figure S3) at $77 \mathrm{~K}$ using BET method. The specific surface area was $104.42 \mathrm{~m}^{2} \mathrm{~g}^{-1}$ for GO supported $\mathrm{ZnS}$ nanoweb and $75.83 \mathrm{~m}^{2} \mathrm{~g}^{-1}$ for individual $\mathrm{ZnS}$. GO grows two dimensionally (2D) with large specific surface area, therefore, it increased the specific surface area of $\mathrm{ZnS}$ nanoweb deposited on it, which is suitable for high electrochemical performance. 31,32

\subsection{Electrochemical Testing by Three electrodes}

The electrochemical testing are performed using three electrodes system to elucidate the electrochemical behavior of individual $\mathrm{ZnS}$ layer and GO supported $\mathrm{ZnS}$ nanoweb. Hence, potential supercapacitor applications can be evaluated. The electrochemical performance of the fabricated GO thin film has been already reported in a previous report. $27 \mathrm{GO}$ has found playing effective character for optimizing the electrochemical nature of the metal sulfide layer. 27 The cyclic voltammetry (CV) was performed in a $2 \mathrm{M} \mathrm{KOH}$ electrolyte, and the $\mathrm{CV}$ 
curves measured at different scan rates are plotted in Fig. 3. It is quite evident from Fig. 3 (a) that individual $\mathrm{ZnS}$ showed good redox peaks in potential window $0.0-0.60 \mathrm{~V}$ revealing its pseudocapacitive behavior. 33 The specific capacitance, as determined using CV plots, was calculated using Eq. 1,

$$
\mathrm{C}_{\mathrm{s}}=\frac{\int_{\mathrm{V}_{\mathrm{c}}}^{\mathrm{V}_{\mathrm{a}}} \mathrm{I} * \mathrm{dV}}{\mathrm{m} * \mathrm{~S} * \Delta \mathrm{V}}
$$

Where, I and dV express current and the potential values extracted from the redox peaks. The symbols $\mathrm{m}, \mathrm{S}$ and $\Delta \mathrm{V}$ express the fabricated active mass, the scan rate applied and the potential window set for the $\mathrm{CV}$ test. The measured specific capacitance of individual $\mathrm{ZnS}$ was $1240.62,1200.43$ and $1040.80 \mathrm{Fg}^{-1}$ at 2,5 and $10 \mathrm{mVs}^{-1}$, respectively. Fig. 3 (b) shows the CV graphs measured for GO supported $\mathrm{ZnS}$ nanoweb fabricated on NF substrate. The CV curve measured for $\mathrm{ZnS}$ nanoweb exhibited well resolved redox peaks, however, potential was slightly shifted to a higher regime with the increasing scan rate $\left(2,5,10,15\right.$ and $20 \mathrm{mVs}^{-}$ ${ }^{1}$ ), suggesting pseudocapacitive behavior of the material. 34 Thus, GO supported $\mathrm{ZnS}$ nanoweb exhibited significantly large $\mathrm{CV}$ behavior and greater potential window as compared to those shown by individual $\mathrm{ZnS}$. Moreover, a potential window of $0.8 \mathrm{~V}$ was found for GO supported $\mathrm{ZnS}$ nanoweb, which is greater than many reported works. 30 Such a larger potential window of $\mathrm{GO}$ supported $\mathrm{ZnS}$ nanoweb is attributed to more thermodynamically active available GO sites relative to individual ZnS. Fig. 3 (c) shows the redox current at various scan rates that increased linear against square-root of scan rate, confirming the pseudocapacitor like nature for GO supported $\mathrm{ZnS}$ nanoweb. 35 The GO supported ZnS nanoweb also showed excellent specific capacitance of 3052, 2625.82 and $2105.70 \mathrm{Fg}^{-1}$, respectively, at 2,5 and $10 \mathrm{mVs}^{-1}$, larger than that by the individual $\mathrm{ZnS}$ electrode. Such a large improvement might be originated due to the nanoweb like surface structure, associated with the higher electrical conductivity values as well as the greater specific surface area. 36 

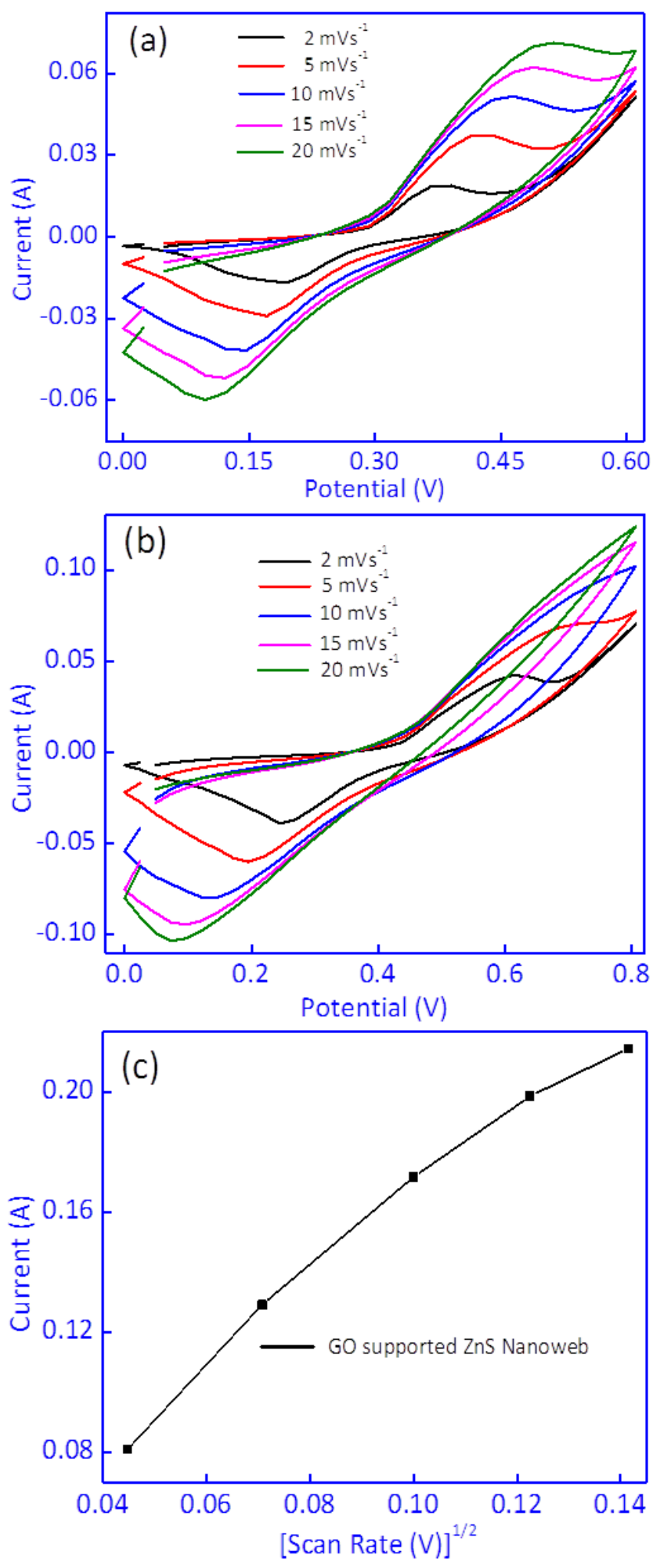

Figure 3: The $\mathrm{CV}$ curves measured for (a) individual $\mathrm{ZnS}$ and (b) GO supported $\mathrm{ZnS}$ nanoweb. (c) The linearly increased redox current as function of square root of the scan rates for $\mathrm{GO}$ supported $\mathrm{ZnS}$ nanoweb. 
The galvanostatic charge-discharge (GCD) profile for individual $\mathrm{ZnS}$ and GO supported $\mathrm{ZnS}$ nanoweb using three electrode systems is shown in Fig. 4. As evident from Fig. 4 (a), the GCD profile for only ZnS showed discharge time 471s, 230s, 150s and 94s at (current densities) 3, 5, 10 and $15 \mathrm{mAcm}^{-2}$, respectively. The specific capacitance $\mathrm{C}_{\mathrm{s}}$ of individual ZnS on NF substrate was calculated using the following Eq. 2,

$$
\mathrm{C}_{\mathrm{s}}=\frac{\mathrm{I}}{\mathrm{m} * \frac{\mathrm{dV}}{\mathrm{dt}}}
$$

Where, $\mathrm{dV} / \mathrm{dt}$ expresses the slope region in the GCD curve, $\mathrm{m}$ represents the active mass per $\mathrm{cm}$ of the electrode material and I is the current applied during GCD test. The calculated specific capacitance for individual $\mathrm{ZnS}$ was $1296.51,1334,1055.18$ and $922.50 \mathrm{Fg}^{-1}$, respectively, at $3,5,10$ and $15 \mathrm{mAcm}^{-2}$. The energy $\left(\mathrm{E}_{\mathrm{d}}\right)$ and power densities $\left(\mathrm{P}_{\mathrm{d}}\right)$ were calculated using Eq. 3 \& 4, respectively. 37

$$
\begin{aligned}
\mathrm{E}_{\mathrm{d}} & =0.5 \mathrm{C}_{\mathrm{s}}(\Delta \mathrm{V})^{2} \\
\mathrm{P}_{\mathrm{d}} & =\frac{\mathrm{E}_{\mathrm{d}}}{\mathrm{t}}
\end{aligned}
$$

Where, $\Delta \mathrm{V}$ and $\mathrm{t}$ represents potential window and discharge time, respectively. The energy density for individual $\mathrm{ZnS}$ was 45, 46.32, 37 and $32 \mathrm{WhKg}^{-1}$ at the current densities 3, 5, 10 and $15 \mathrm{mAcm}^{-2}$, respectively. The individual $\mathrm{ZnS}$ showed maximum $\mathrm{C}_{\mathrm{s}}$ of $1334 \mathrm{Fg}^{-1}$ and an energy density $46.32 \mathrm{WhKg}^{-1}$ was measured at the current density $5 \mathrm{mAcm}^{-2}$. The individual $\mathrm{ZnS}$ exhibited power density of $344,725,887.65$ and $1226.70 \mathrm{WKg}^{-1}$ at energy density 45 , 46.32, 37 and $32 \mathrm{WhKg}^{-1}$, respectively.

The GO supported $\mathrm{ZnS}$ nanoweb showed excellent electrochemical properties indicating its suitability as electrode material for supercapacitors applications. Fig. 4 (b) revealed GO supported ZnS nanoweb exhibit good discharge times of 592, 321, 181 and 95 s, at 3, 5, 10 and $15 \mathrm{mAcm}^{-2}$, respectively. A large plateau region in $\mathrm{CV}$ curves confirmed the pseudocapacitive behavior of GO supported ZnS nanoweb fabricated on the NF substrate. 34, 
38, 39 The specific capacitances and energy densities were measured using Eq. $2 \& 3$, respectively. The specific capacitance and the energy densities measured for GO supported $\mathrm{ZnS}$ nanoweb electrode at the current densities 3,5,10,15 $\mathrm{mAcm}^{-2}$ were found as 2400.30 , 2345.70, 2219, 2326.31 $\mathrm{Fg}^{-1}$ and 120, 117.30, 111, 116.32 $\mathrm{WhKg}^{-1}$, respectively. Both the specific capacitance as well as the energy density measured for GO supported $\mathrm{ZnS}$ nanoweb were found significantly larger than that by the GO layer and individual $\mathrm{ZnS}$ prepared on NF. The enhanced values might be appeared due to the mechanical support offered by the GO thin film causing the $\mathrm{ZnS}$ nanoweb to exhibit delayed discharging character, and hence, improved electrochemical behavior was resulted. 16, 17, 34 Moreover, the large electrical conductivity of $\mathrm{ZnS}$ nanoweb facilitated the easy electronic transfers at the electrode surface, which showed optimized electrochemical behavior. The charge transfer resulting in charge storage mechanism is shown in below scheme. 30,40

$$
\mathrm{ZnS}+\mathrm{KOH} \longleftrightarrow \mathrm{ZnSOH}+\mathrm{e}^{-1}+\mathrm{K}^{+1}
$$

The GO supported $\mathrm{ZnS}$ nanoweb showed maximum specific capacitance and energy density 2400.27 $\mathrm{Fg}^{-1}$ and $120 \mathrm{WhKg}^{-1}$, respectively, at $3 \mathrm{mAcm}^{-2}$. However specific capacitance and energy density were decreased with the current density, which illustrated that higher excitation result GO supported $\mathrm{ZnS}$ nanoweb to exhibit large polarization and become more resistive for the electrolyte ion diffusion or the charge transfer. 16, 40, 41 Furthermore, the measured higher electrochemical parameters were also found related to the improved electrical conductivity and specific surface area of GO supported $\mathrm{ZnS}$ nanoweb as compared to the $\mathrm{ZnS}$ fabricated on NF. 42 The measured specific capacitance was excellent and much larger than previously reported materials (see Table 1). Similarly, energy density of GO supported $\mathrm{ZnS}$ nanoweb was also found much higher than those in many previous reports. ${ }^{34}$, 
38, 43-45 The GO supported ZnS nanoweb electrode delivered power density 730, 1315.34, 2206.63 and $4407.73 \mathrm{WKg}^{-1}$ at the energy density $120,117.30,111$ and $116.32 \mathrm{WhKg}^{-1}$, respectively. The maximum power density $4407.73 \mathrm{WKg}^{-1}$ was found very high as compared to those in the reported literature. 34, 40, 45 The results suggested that $\mathrm{ZnS}$ nanoweb prepared on GO layer acting as the electrode exhibit excellent electrochemical behavior suitable for applications in asymmetric supercapacitor.

Table 1: Comparison of specific capacitance GO supported $\mathrm{ZnS}$ nanoweb electrode measured at various electrochemical parameters of using three electrode GCD systems other electrode materials.

\begin{tabular}{lllllll}
\hline S. no & Material & Substrate & Solution & Current & $\mathrm{C}_{\mathrm{s}}\left(\mathrm{Fg}^{-1}\right)$ & Reference \\
& & & M KOH & density & \\
& & NF & 6 & $5 \mathrm{mVs}^{-1}$ & 197.1 & 30
\end{tabular}

Nanocomposites

\begin{tabular}{|c|c|c|c|c|c|c|}
\hline 2 & $\mathrm{CoS}$ & $\mathrm{NF}$ & 6 & $1 \mathrm{Ag}^{-1}$ & 564 & 46 \\
\hline 3 & $\mathrm{Ni}-\mathrm{Co}-\mathrm{S}-6$ & $\mathrm{NF}$ & 6 & $2 \mathrm{Ag}^{-1}$ & 1304 & 47 \\
\hline \multirow[t]{2}{*}{4} & CC-NC-LDH & Carbon & 6 & $1 \mathrm{Ag}^{-1}$ & 1817 & 48 \\
\hline & Hybrid & Cloth & & & & \\
\hline 5 & TP-NixSy/rGO & $\mathrm{NF}$ & 2 & $1 \mathrm{Ag}^{-1}$ & 2074 & 49 \\
\hline 6 & $\mathrm{NiCo}_{2} \mathrm{~S}_{4} / \mathrm{MWCNTs}$ & NF & 6 & $1 \mathrm{~A} / \mathrm{g}$ & 2080 & 43 \\
\hline 7 & $\mathrm{NiS}$ & $\mathrm{NF}$ & 6 & $1 \mathrm{Ag}^{-1}$ & 2112 & 50 \\
\hline \multirow[t]{2}{*}{8} & GO supported $\mathrm{Al}_{2} \mathrm{~S}_{3}$ & $\mathrm{NF}$ & 2 & $3 \mathrm{mAcm}^{-2}$ & 2178.16 & 40 \\
\hline & nanorambutan & & & & & \\
\hline \multirow[t]{2}{*}{9} & GO supported $\mathrm{ZnS}$ & $\mathrm{NF}$ & 2 & $3 \mathrm{mAcm}^{-2}$ & 2400.30 & This work \\
\hline & nanoweb & & & & & \\
\hline
\end{tabular}



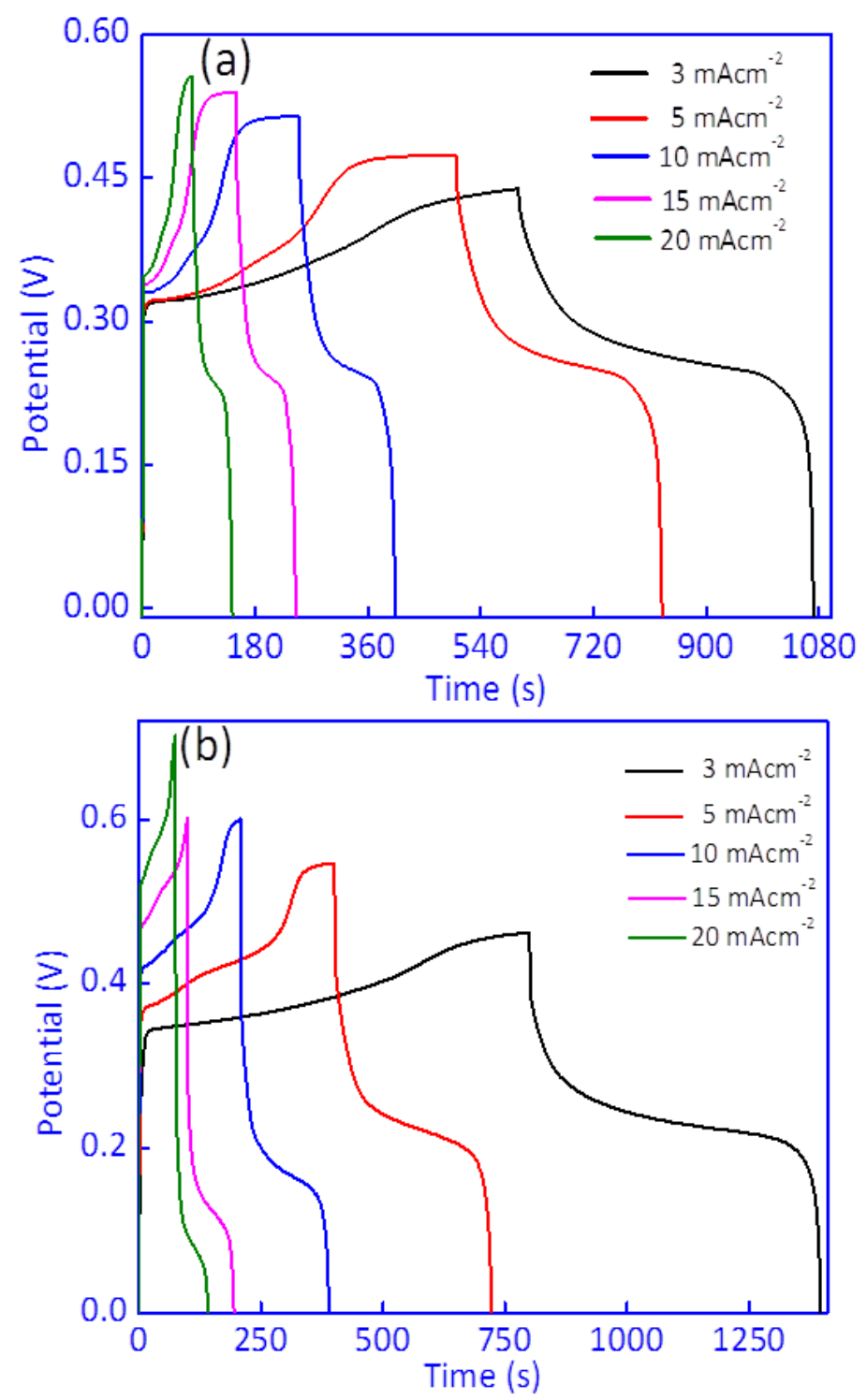

Figure 4: Galvanostatic charge-discharge profile of (a) individual ZnS and (b) GO supported ZnS nanoweb on NF under varying current density.

Nyquist plot presented in the Fig. 5 (a) illustrates the real resistance Z' versus imaginary parts Z" of electrochemical impedance for GO supported $\mathrm{ZnS}$ nanoweb and individual $\mathrm{ZnS}$. Observed equivalent series resistance was 1.56 and $2.96 \Omega$ for GO supported $\mathrm{ZnS}$ nanoweb and individual $\mathrm{ZnS}$ individual $\mathrm{ZnS}$ on $\mathrm{NF}$ substrate, which corresponds series equivalent resistant for individual $\mathrm{ZnS}$ was greater than GO supported $\mathrm{ZnS}$ nanoweb. The zoom area of inset Fig. 5 (a) reveals to smaller kink at the high frequency region for GO supported $\mathrm{ZnS}$ 
nanoweb corresponds to a small semicircle, which indicates very smaller contact and charge resistances. The straight line in the low frequency region exhibits a slope higher for GO supported $\mathrm{ZnS}$ nanoweb as compared to the individual $\mathrm{ZnS}$ (Fig. 5 (a)) at the same conditions. Such a larger slope represents smaller Warburg resistance. Hence, the use of GO thin film improved the conductive network of $\mathrm{ZnS}$ nanoweb and making it more suitable for electrochemical applications. Such GO mediated enhancement in the electrical conduction was also found before consistent with the observation from CV and GCD curves in this study. The more conductive nature of $\mathrm{ZnS}$ nanoweb may be ascribed to the high electrical conductivity and greater effective surface area. 51

The electrode stability, of GO supported $\mathrm{ZnS}$ nanoweb and individual $\mathrm{ZnS}$, was evaluated using CV curves (see Fig. 5 (b)). The electrode stability testing is mostly employed to observe the supercapacitor applcations. For example, Pujari et al. (2016) investigated the electrode stability of MnS nanofiber using CV analysis. Simmilarly Patil et al. (2017) employed the $\mathrm{CV}$ data for testing the electrode stability to evaluate the aymmetric supercapcitor applications of $\mathrm{Co}_{3} \mathrm{~S}_{4} / \mathrm{Co}_{3} \mathrm{~S}_{4}-\mathrm{rGO}$. The GO supported $\mathrm{ZnS}$ nanoweb, even after 1000 cycles retained $95.90 \%$ of the specific capacitance, while individual $\mathrm{ZnS}$ showed only $53.6 \%$ retention. The excellent specific capacitance retention exhibited by GO supported $\mathrm{ZnS}$ nanoweb was attributed to the nanoweb like surface structure and significantly higher specific area, which can activate the electrode for conduction, in contrast to that in the individual ZnS. 44, 52 Structural stability was also observed by XRD after electrochemical testing as given in Fig. S4, which showed that although intensity has been reduced but peaks are still appeared at the same positions corresponding to GO supported $\mathrm{ZnS}$ nanoweb. 

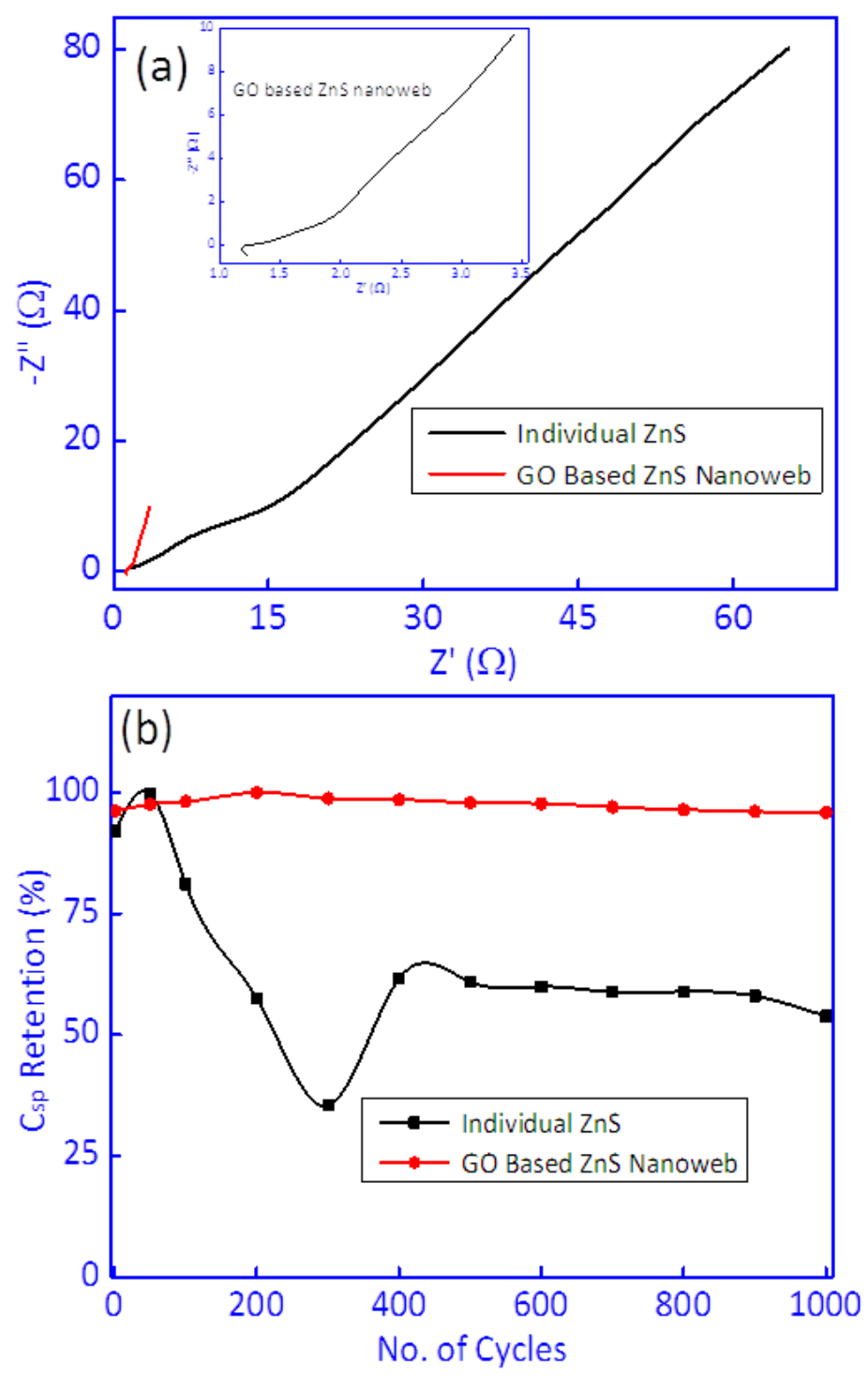

Figure 5: (a) Nyquist plot for GO supported ZnS Nanoweb and individual ZnS (b) electrode stability test for GO supported $\mathrm{ZnS}$ nanoweb and individual $\mathrm{ZnS}$ fabricated on NF substrate.

\subsection{Two Electrodes Symmetric System}

The electrochemical behavior was also elucidated using two electrode system for observing the symmetric supercapacitor applications. Two electrodes were formed using GO supported $\mathrm{ZnS}$ nanoweb, which were separated by the filter paper, sandwiched by the current collector (gold deposited $\mathrm{Cu}$ foil) and sealed into the coffee bag. The CV and GCD measurements using two symmetric GO supported $\mathrm{ZnS}$ nanoweb electrodes were performed with Autolab PGSTAT 12. Fig. 6 (a \& b) shows CV curves at the scan rate 2, 5, 15 and $20 \mathrm{mVs}^{-1}$ and GCD 
curves at the current density $0.50,1$ and $2 \mathrm{mAcm}^{-2}$, respectively, for GO supported $\mathrm{ZnS}$ nanoweb on NF substrate. The measured CV curves (Fig. 6 a) revealed that GO supported $\mathrm{ZnS}$ nanoweb shows double redox peaks within -0.4 to $0.4 \mathrm{~V}$ confirming the pseudocapacitive character of this material. The double oxidation and reduction peaks showed that redox reactions occur two times, which was justified due to gold-plated $\mathrm{Cu}$ sheets employed for as the current sensor. Similarly, GCD profile (Fig. 6 b) also manifested two redox reactions for demonstrating the underlying pseudocapacitive behavior of GO supported $\mathrm{ZnS}$ nanoweb fabricated on NF substrate. The possible charge storage mechanism, as shown in Fig. 7, indicated that $\mathrm{OH}^{-1}$ moves easily from one electrode surface to another electrode, which may result because of the optimum conductivity and suitable large specific surface area of the electrode surface available during the charge and discharge process. ${ }^{27}$ The specific capacitance was computed using the following Eq. 5. 49, 53

$$
\mathrm{C}_{\mathrm{s}}=\frac{2 * \mathrm{I}}{\mathrm{m} * \frac{\mathrm{dV}}{\mathrm{dt}}}
$$

The symbols $\mathrm{m}$ and I show the active mass of the electrode and the current applied during GCD. The specific capacitance determined for GO supported ZnS nanoweb was 131.30, 228.30 and $175.92 \mathrm{Fg}^{-1}$ at the current density $0.50,1$ and $2 \mathrm{mAcm}^{-2}$, respectively. The GO supported $\mathrm{ZnS}$ nanoweb exhibited the maximum specific capacitance $228.30 \mathrm{Fg}^{-1}$ at $1 \mathrm{mAcm}^{-}$ 2. It was found that GO supported $\mathrm{ZnS}$ nanoweb remains less active at the smaller current density, while it polarizes due to larger resistivity at higher current density. However, 1 $\mathrm{mAcm}^{-2}$ was appropriate for the efficiently excitation of the GO supported $\mathrm{ZnS}$ nanoweb associated with the suppressed polarization. The energy density determined for GO supported ZnS nanoweb, using Eq. 3, was 11.67, 20.29 and 15.64 $\mathrm{WhKg}^{-1}$ at current density 0.50, 1 and $2 \mathrm{mAcm}^{-2}$, respectively. The GO supported $\mathrm{ZnS}$ nanoweb exhibited the maximum energy density 20.29 $\mathrm{WhKg}^{-1}$ at $2 \mathrm{mAcm}^{-2}$ using two electrode system. The larger energy density for 
the GO supported $\mathrm{ZnS}$, grown by a very simple and inexpensive growth method, illustrates an advantage over the molybdenum sulfide and nitrogen-doped carbon nanofibers supported flexible supercapacitor prepared using complicated synthesis technique, exhibited energy density $5.42 \mathrm{WhKg}^{-1}$ and $10.96 \mathrm{WhKg}^{-1}$, as reported by Javed et al. (2015) and Chen et al. (2017), respectively. 2, 54 The GO supported ZnS nanoweb exhibited power density 154.50, 227.58 and $485.30 \mathrm{WKg}^{-1}$ at the energy density $11.67,20.29$ and $15.64 \mathrm{WhKg}^{-1}$, respectively. The symmetric behavior of individual $\mathrm{ZnS}$ on $\mathrm{NF}$ substrate was also investigated under similar conditions, which is shown in Fig. 6 (c \& d). Fig. 6 (c) shows CV curves measured for individual $\mathrm{ZnS}$ in the potential window -0.3 to $0.4 \mathrm{~V}$ at the scan rate $2,5,15$ and $20 \mathrm{mVs}^{-1}$. It was found that individual $\mathrm{ZnS}$ also exhibit faradaic reactions similar to those observed for GO supported $\mathrm{ZnS}$ nanoweb. Interestingly, the potential window for GO supported $\mathrm{ZnS}$ nanoweb is higher than for the individual $\mathrm{ZnS}$, and this observation similar that from the three electrode systems. Such improvement was found due to GO thin film that optimizes the surface morphological impacts and the electrical conductivity of $\mathrm{ZnS}$ nanoweb. Hence, the potential window for GO supported $\mathrm{ZnS}$ nanoweb was found equal to $0.8 \mathrm{~V}$ in both two and three electrodes system, however, a shift towards the positive region was also observed, suggesting that GO supported $\mathrm{ZnS}$ nanoweb is suitable for the supercapacitors operating for the positive potential window. The individual $\mathrm{ZnS}$ exhibited poor specific capacitance, energy density and power density as compare to GO supported $\mathrm{ZnS}$ nanoweb. The specific capacitance and the energy density determined for individual $\mathrm{ZnS}$ from the GCD profile (Fig. 6 d) was found as 102.45, 101.20, 72.64 $\mathrm{Fg}^{-1}$ and $6.97,6.90,4.94 \mathrm{WhKg}^{-1}$ at $0.50,1,2$ $\mathrm{mAcm}^{-2}$, respectively. While the power density of individual $\mathrm{ZnS}$ was found as 102.88 , 229.57 and 494.36 $\mathrm{WhKg}^{-1}$ at the energy density $6.97,6.90$ and $4.94 \mathrm{WhKg}^{-1}$, respectively. 

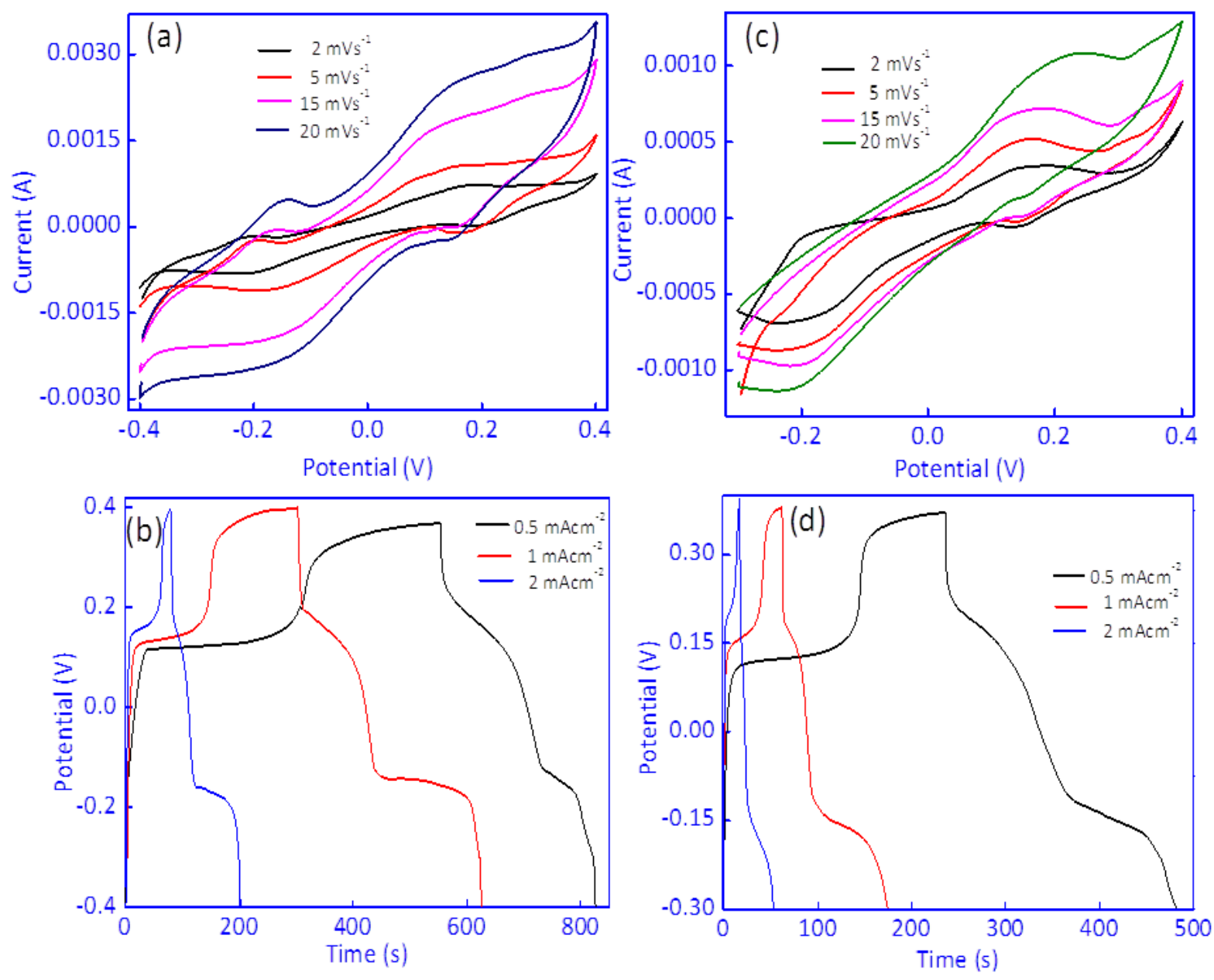

Figure 6: The (a) CV plots and (b) GCD profiles measured for GO supported ZnS nanoweb.

The (c) CV plots and (d) GCD nature measured for individual ZnS on NF substrate. The measurements were performed using two electrodes symmetric system.

Owing to good two electrodes symmetric behavior of GO supported $\mathrm{ZnS}$ nanoweb endorsed to observe two electrodes stability and EIS test. Hence, two electrodes symmetric test for GO supported $\mathrm{ZnS}$ nanoweb was measured at same electrochemical conditions up to 1000 cycles (Fig. 6 (b)). Inset images showed the $1^{\text {st }}, 500^{\text {th }}$ and $1000^{\text {th }}$ cycles, those revealed that the cyclic behavior changed with e passage of time. Stability curves revealed that $\mathrm{C}_{\mathrm{s}}$ reduced abruptly up to $57 \%$ in first 50 cycles, which might be due to some kind of activation of materials but later reduced slowly. $\mathrm{C}_{\mathrm{s}}$ retention up to 450 cycles revealed $36 \%$ but it retained up to $27 \%$ after 100 cycles. After 50 cycles, the decreasing way of $\mathrm{C}_{\mathrm{s}}$ suggested nearly linear 
and good stability. EIS data (Fig. 7 (c)) revealed a huge semicircle in low frequency and straight line in high frequency region. Large semicircle showed series equivalent resistance of $497 \Omega$, so in symmetric behavior, the whole conduction was due to electrode structures instead of standard electrodes. Further the inset images showed the series equivalent circuit for GO supported $\mathrm{ZnS}$ nanoweb, it revealed the same solution resistance $\left(\mathrm{R}_{\mathrm{s}}\right)$ and charge transfer resistance $\left(\mathrm{R}_{\mathrm{ct}}\right)$ of $9.31 \Omega$. Capacitance and double layer capacitance was 3.77 and $634 \mathrm{uF}$ respectively, while Warburg resistance was very small as $23.9 \mathrm{u} \Omega$ as straight line showed that Warburg resistance is small as compare to charge transfer and solution resistance. 

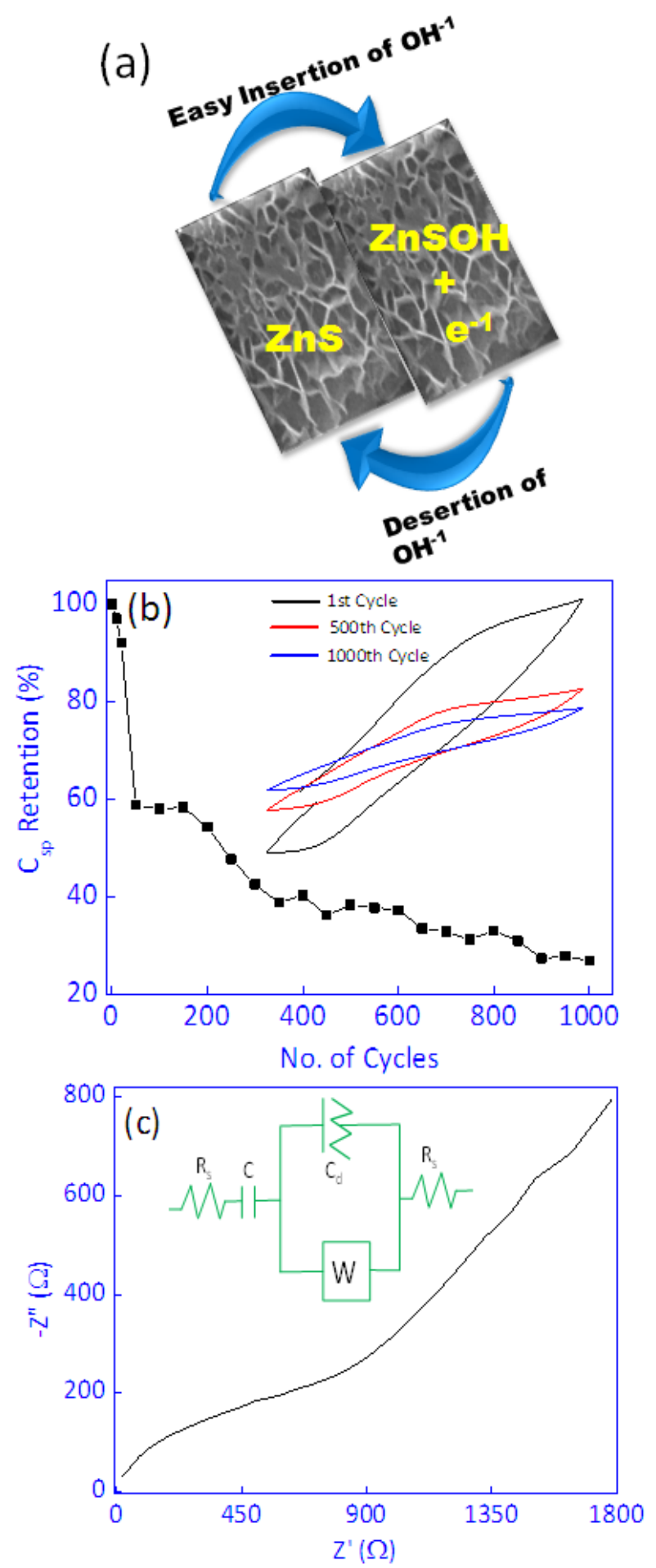

Figure 7: A schematic illustration of the charge storage mechanism in GO supported $\mathrm{ZnS}$ nanoweb (b) Electrode stability test and (c) electrochemical impedance spectroscopy for Symmetric GO supported ZnS nanoweb. 


\section{Conclusion}

In supercapacitors applications, morphology of a material is a key parameter to enhance the electrical conductivity and specific surface area. We undertake here controlled synthesis of $\mathrm{ZnS}$ nanoweb deposited directly on thin layer graphene oxide (GO) modified Ni foam. The growth of $\mathrm{ZnS}$ (having nanoweb like surface observed using SEM) on the NF pre-deposited with GO layer was confirmed from the XRD analysis. The GO supported $\mathrm{ZnS}$ nanoweb was showed exhibiting good electrical conductivity $100.15 \mathrm{Scm}^{-1}$ and the specific surface area $104.42 \mathrm{~m}^{2} \mathrm{~g}^{-1}$. The excellent specific capacity $2400.30 \mathrm{Fg}^{-1}$ and energy density $120 \mathrm{WhKg}^{-1}$ were measured at current density $3 \mathrm{mAcm}^{-2}$ using three electrode systems, while the power density $4407.73 \mathrm{WKg}^{-1}$ was found at $15 \mathrm{mAcm}^{-2}$. The excellent electrochemical performance observed was justified due to the excellent value of the electrical conductivity, greater area of the effective surface. The two electrode symmetric measurements of GO supported $\mathrm{ZnS}$ nanoweb also gave good energy density $20.29 \mathrm{WhKg}^{-1}$ at $2 \mathrm{mAcm}^{-2}$. Hence, both symmetric and asymmetric measurements of GO supported $\mathrm{ZnS}$ nanoweb suggested it as the most excellent electrode for supercapacitor applications.

\section{Experimental Section}

Modified Hummers and Offenmans method was applied for fabrication of GO and thin film on nickel foam substrate was deposited through using ultra-sonication, for details see our previous work. 27 The GO supported $\mathrm{ZnS}$ nanoweb was finally synthesized using hydrothermal process. For the hydrothermal synthesis, $0.05 \mathrm{M} \mathrm{Zn}\left(\mathrm{CH}_{3} \mathrm{COO}\right)_{2} . \mathrm{H}_{2} \mathrm{O}$ solution was prepared in a canonical flask and $0.05 \mathrm{M} \mathrm{K}_{2} \mathrm{~S}$ solution was added drop-wise using burette under continuous stirring at magnetic stirrer. The NF having GO thin layer was also immersed into the solution. The formed precipitates and the immersed NF having predeposited GO were transferred to a Teflon lined stainless steel autoclave that was subjected to $150{ }^{\circ} \mathrm{C}$ for $4 \mathrm{~h}$ using an electric oven. A schematic illustration showing this synthesis process 
is given as Fig. 8. The final fabricated product on NF with pre-deposited GO after washing with deionized water was dried at $50{ }^{\circ} \mathrm{C}$ in electric oven. Moreover, individual $\mathrm{ZnS}$ was also prepared on bare (without GO thin film) NF substrate under similar conditions. Active mass were measured as $2.7,4.8$ and $6.2 \mathrm{mg}$ per $\mathrm{cm}^{2}$ for GO thin film, individual $\mathrm{ZnS}$ and GO supported $\mathrm{ZnS}$, respectively. A reaction resulted the formation of $\mathrm{ZnS}$ could be expressed as:

$$
\mathrm{Zn}\left(\mathrm{CH}_{3} \mathrm{COO}\right)_{2} .2 \mathrm{H}_{2} \mathrm{O}_{(\mathrm{aq})}+\mathrm{K}_{2} \mathrm{~S}_{(\mathrm{aq})} \longrightarrow \mathrm{ZnS}+2 \mathrm{CH}_{3} \mathrm{COOK}+\mathrm{nH}_{2} \mathrm{O}
$$

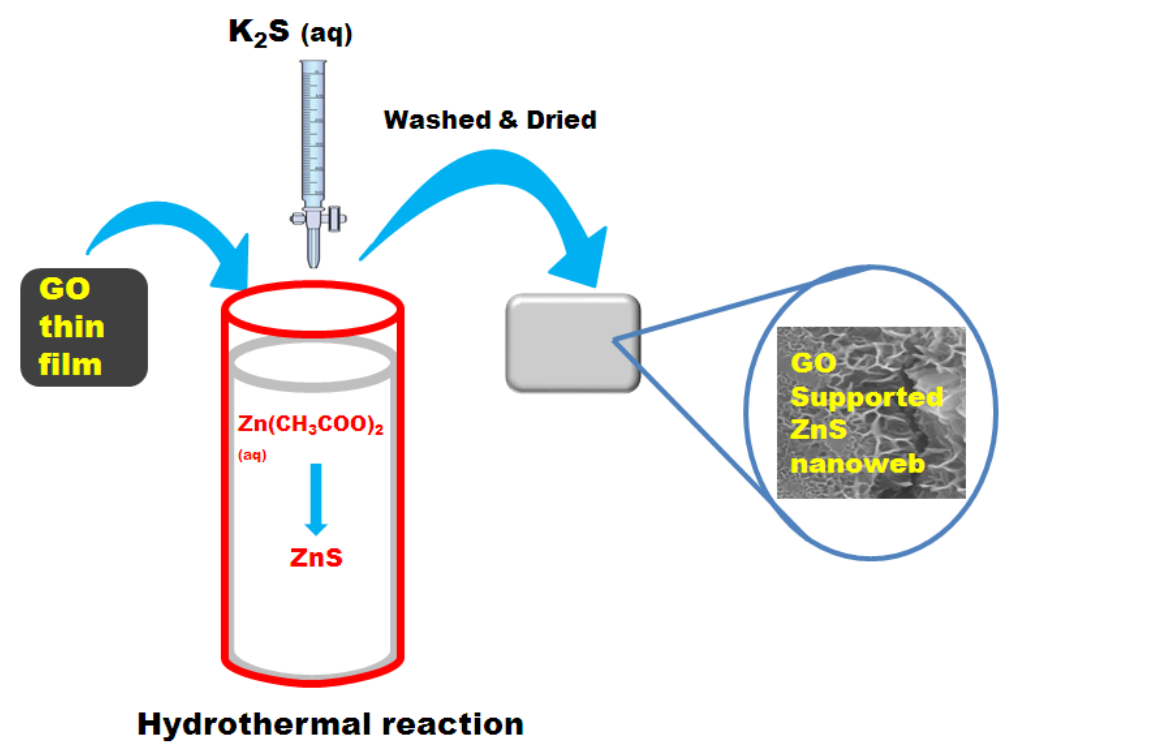

Figure 8: Synthesis process for GO supported $\mathrm{ZnS}$ nanoweb

\subsection{Characterization}

The structural properties were revealed using X-ray diffractometer (Rigaku Smart lab) by employing $\mathrm{CuK}_{\alpha} \mathrm{X}$-rays within $2 \theta$ range $5-80^{\circ}$. The surface study was carried out using SEM (JEOL, SM6490). Elemental atomic ratio was observed by energy dispersive X-ray technique (EDX). Electrical measurements were done at room temperature using four-probe method (ISO (9001-2000) SVS/NC). Moreover, specific surface area was elucidated by applying BET procedure.

Various electrochemical measurements i.e., cyclic voltammetry (CV), galvanostatic chargedischarge (GCD) and electrochemical impedance spectroscopy (EIS) have been performed by employing Autolab PGSTAT12 workstation and Nova software. A 2M KOH electrolytic 
solution was employed in the measurement performed using three electrode system (with the platinum-wire as counter electrode, $\mathrm{Ag} / \mathrm{AgCl}$ as reference electrode, synthesized product on $\mathrm{NF}$ as working electrode material). In addition, symmetric behavior of GO supported $\mathrm{ZnS}$ nanoweb electrode has also been observed for supercapacitor applications. For the symmetric measurements, both working electrodes were shielded by using filter paper as a separator, and electrodes were sandwiched by gold-plated $\mathrm{Cu}$ sheets, which were employed as the current sensor.

\section{Acknowledgement}

This work was financially supported by Higher Education Commission of Pakistan (IRSIP program No.1-8/HEC/HRD/2017/8079). This work has been carried out with collaboration at COMSATS Lahore and NIMS Japan.

\section{References}

1. Y. Huang, M. Zhong, F. Shi, X. Liu, Z. Tang, Y. Wang, Y. Huang, H. Hou, X. Xie and C. Zhi, Angewandte Chemie, Intern.in Eng. 2017, 56, 9141-9145.

2. L.-F. Chen, Y. Lu, L. Yu and X. W. Lou, Energy \& Environmental Science, 2017, 10, $1777-1783$.

3. Y. Qiu, X. Zhang and S. Yang, Physical Chemistry Chemical Physics, 2011, 13, 12554-12558.

4. Y. Liu, G. Jiang, S. Sun, B. Xu, J. Zhou, Y. Zhang and J. Yao, Journal of Alloys and Compounds, 2018, 731, 560-568.

5. L. Hu, M. Pasta, F. L. Mantia, L. Cui, S. Jeong, H. D. Deshazer, J. W. Choi, S. M. Han and Y. Cui, Nano Lett, 2010, 10, 708-714.

6. C. Larson, B. Peele, S. Li, S. Robinson, M. Totaro, L. Beccai, B. Mazzolai and R. Shepherd, Science, 2016, 351, 1071-1074.

7. H. Hu, Bu Y. Guan and Xiong W. Lou, Chem, 2016, 1, 102-113. 
8. D. Sheberla, J. C. Bachman, J. S. Elias, C.-J. Sun, Y. Shao-Horn and M. Dinca, Nat Mater, 2017, 16, 220-224.

9. M. Jana, P. Khanra, N. C. Murmu, P. Samanta, J. H. Lee and T. Kuila, Physical Chemistry Chemical Physics, 2014, 16, 7618-7626.

10. Y. Liu, G. Jiang, S. Sun, B. Xu, J. Zhou, Y. Zhang and J. Yao, Journal of Electroanalytical Chemistry, 2017, 804, 212-219.

11. G. Yilmaz, C. X. Guo and X. Lu, ChemElectroChem, 2016, 3, 158-164.

12. C. Nicolò, R. V. Ricardo, D. Willem, S. Linda, B. Koen, D. V. D. E. and F. Jan, ChemElectroChem, 2014, 1, 1182-1188.

13. X. Xia, C. Zhu, J. Luo, Z. Zeng, C. Guan, C. F. Ng, H. Zhang and H. J. Fan Small, 2014, 10, 766-773.

14. H. Chen, G. Jiang, W. Yu, D. Liu, Y. Liu, L. Li, Q. Huang and Z. Tong, Journal of Materials Chemistry A, 2016, 4, 5958-5964.

15. P. Zhang, B. Y. Guan, L. Yu and X. W. D. Lou, Angewandte Chemie, Intern.in Eng., 2017, 56, 7141-7145.

16. M. Khairy and S. A. El-Safty, Chemical Communications, 2014, 50, 1356-1358.

17. J. Kang, A. Hirata, L. Kang, X. Zhang, Y. Hou, L. Chen, C. Li, T. Fujita, K. Akagi and M. Chen, Angewandte Chemie, 2013, 125, 1708-1711.

18. M. S. Javed, S. Dai, M. Wang, Y. Xi, Q. Lang, D. Guo and C. Hu, Nanoscale, 2015, 7, 13610-13618.

19. R. R. Salunkhe, Y. V. Kaneti, J. Kim, J. H. Kim and Y. Yamauchi, Accounts of Chemical Research, 2016, 49, 2796-2806.

20. Z. Tianye, T. M. H., L. Bei, R. Sijia, L. Ying, G. T. S., L. Kwok-Ho, C. In-Suk and B.

S. T., ChemElectroChem, 2018, doi:10.1002/celc.201800467. 
21. H. Huang, J. Zhang, L. Jiang and Z. Zang, Journal of Alloys and Compounds, 2017, 718, 112-115.

22. Z. Zang, X. Zeng, M. Wang, W. Hu, C. Liu and X. Tang, Sensors and Actuators B: Chemical, 2017, 252, 1179-1186.

23. S. S. T. and S. R. Kalai, ChemElectroChem, 2015, 2, 1063-1063.

24. S. Sun, G. Jiang, Y. Liu, Y. Zhang, J. Zhou and B. Xu, Materials Letters, 2017, 197, $35-37$.

25. H. Liang, H. Xiang, L. Zhoubin and W. Zhenhai, ChemElectroChem, 2018, doi:10.1002/celc.201800412.

26. R. Rajesh and R. Kwang-Sun, ChemElectroChem, 2018, doi:10.1002/celc.201800533.

27. M. F. Iqbal, M. N. Ashiq, A. Razaq, M. Saleem, B. Parveen and M.-U. Hassan, Electrochimica Acta, 2018, 273, 136-144.

28. M. F. Iqbal, H. Mahmood Ul, M. N. Ashiq, S. Iqbal, N. Bibi and B. Parveen, Electrochimica Acta, 2017, 246, 1097-1103.

29. Y. Li and Y. Wu, Journal of the American Chemical Society, 2009, 131, 5851-5857.

30. R. Ramachandran, M. Saranya, P. Kollu, B. P. C. Raghupathy, S. K. Jeong and A. N. Grace, Electrochimica Acta, 2015, 178, 647-657.

31. Y. Wang, A. G. El-Deen, P. Li, B. H. L. Oh, Z. Guo, M. M. Khin, Y. S. Vikhe, J. Wang, R. G. Hu, R. M. Boom, K. A. Kline, D. L. Becker, H. Duan and M. B. ChanPark, ACS Nano, 2015, 9, 10142-10157.

32. M. S. Javed, J. Chen, L. Chen, Y. Xi, C. Zhang, B. Wan and C. Hu, Journal of Materials Chemistry A, 2016, 4, 667-674.

33. J. Xing, M. Liao, C. Zhang, M. Yin, D. Li and Y. Song, Physical Chemistry Chemical Physics, 2017, 19, 14030-14041. 
34. K. Krishnamoorthy, G. K. Veerasubramani, S. Radhakrishnan and S. J. Kim, Chemical Engineering Journal, 2014, 251, 116-122.

35. P. Simon, Y. Gogotsi and B. Dunn, Science, 2014, 343, 1210-1211.

36. H. Tong, W. Bai, S. Yue, Z. Gao, L. Lu, L. Shen, S. Dong, J. Zhu, J. He and X. Zhang, Journal of Materials Chemistry A, 2016, 4, 11256-11263.

37. N. S. Arul, L. S. Cavalcante and J. In Han, Journal of Solid State Electrochemistry, 2018, 22, 303-313.

38. Y. Zhang, J. Xu, Y. Zheng, Y. Zhang, X. Hu and T. Xu, Nanoscale Research Letters, 2017, 12, 412.

39. W. Fu, W. Han, H. Zha, J. Mei, Y. Li, Z. Zhang and E. Xie, Physical Chemistry Chemical Physics, 2016, 18, 24471-24476.

40. M. F. Iqbal, H. Mahmood Ul, M. N. Ashiq, S. Iqbal, N. Bibi and B. Parveen, Electrochimica Acta, 2017, 246, 1097-1103.

41. L. Lim, Y. Liu, W. Liu, R. Tjandra, L. Rasenthiram, Z. Chen and A. Yu, ACS Applied Materials \& Interfaces, 2017, 9, 39576-39583.

42. R. R. Salunkhe, J. Tang, N. Kobayashi, J. Kim, Y. Ide, S. Tominaka, J. H. Kim and Y. Yamauchi, Chemical Science, 2016, 7, 5704-5713.

43. P. Wen, M. Fan, D. Yang, Y. Wang, H. Cheng and J. Wang, Journal of Power Sources, 2016, 320, 28-36.

44. R. B. Pujari, A. C. Lokhande, A. A. Yadav, J. H. Kim and C. D. Lokhande, Materials \& Design, 2016, 108, 510-517.

45. R. Li, S. Wang, Z. Huang, F. Lu and T. He, Journal of Power Sources, 2016, 312, $156-164$.

46 X. Meng, J. Deng, J. Zhu, H. Bi, E. Kan and X. Wang, Scientific Reports, 2016, 6, 21717-26. 
47. X. Li, Q. Li, Y. Wu, M. Rui and H. Zeng, ACS Applied Materials \& Interfaces, 2015, 7, 19316-19323.

48. S. Li, C. Yu, J. Yang, C. Zhao, M. Zhang, H. Huang, Z. Liu, W. Guo and J. Qiu, Energy \& Environmental Science, 2017, 10, 1958-1965.

49. S. Dai, B. Zhao, C. Qu, D. Chen, D. Dang, B. Song, B. M. deGlee, J. Fu, C. Hu, C.-P. Wong and M. Liu, Nano Energy, 2017, 33, 522-531.

50. X.-Y. Yu, L. Yu, H. B. Wu and X. W. Lou, Angewandte Chemie International Edition, 2015, 54, 5331-5335.

51. A. A. AbdelHamid, X. Yang, J. Yang, X. Chen and J. Y. Ying, Nano Energy, 2016, 26, 425-437.

52. S. J. Patil, J. H. Kim and D. W. Lee, Journal of Power Sources, 2017, 342, 652-665.

53. M. M. Shaijumon, F. S. Ou, L. Ci and P. M. Ajayan, Chemical Communications, 2008, 2373-2375.

54. M. S. Javed, S. Dai, M. Wang, D. Guo, L. Chen, X. Wang, C. Hu and Y. Xi, Journal of Power Sources, 2015, 285, 63-69. 